\title{
CD47 regulates the TGF- $\beta$ signaling pathway in osteoblasts and is distributed in Meckel's cartilage
}

\author{
Koichi Shimada ${ }^{1,3)}$, Akira Nakajima ${ }^{2,3)}$, Kyoko Ikeda ${ }^{1)}$, Kazuya Ishibashi ${ }^{1)}$, \\ Noriyoshi Shimizu ${ }^{2,3}$ and Koichi Ito ${ }^{1,3)}$ \\ ${ }^{1)}$ Department of Periodontology, Nihon University School of Dentistry, Tokyo, Japan \\ ${ }^{2}$ Department of Orthodontics, Nihon University School of Dentistry, Tokyo, Japan \\ ${ }^{3)}$ Division of Advanced Dental Treatment, Dental Research Center, Nihon University School of Dentistry, \\ Tokyo, Japan
}

(Received 18 January and accepted 1 March 2011)

\begin{abstract}
Previously, CD47 gene expression has been shown to increase during mandible development using a micro array technique. To determine the function of CD47 in osteoblasts, CD47 was silenced using siRNA in vitro. The TGF- $\beta 1$ and phosphorylatedSmad2 levels and transcription factor genes related to bone metabolism increased dose-dependently with CD47 silencing. Furthermore, we determined the distribution of CD47 in mouse embryonic E13 and E15 in vivo. The CD47-positive cells were localized in Meckel's cartilage and antenatal mandibular bone. These results suggest that TGF- $\beta 1$ signaling and mandible development might be regulated by CD47. (J Oral Sci 53, 169-175, 2011)
\end{abstract}

Keywords: CD47; TGF- $\beta$; osteoblasts; Meckel's cartilage; mandibular development.

\section{Introduction}

The transforming growth factor- $\beta$ (TGF- $\beta$ ) superfamily including bone morphogenetic proteins (BMPs) has important functions in osteoblast differentiation and maturation in vitro and in bone formation in vivo. TGF- $\beta$ binds to TGF- $\beta$ types I and II serine/threonine kinase

Correspondence to Dr. Koichi Shimada, Department of Periodontology, Nihon University School of Dentistry, 1-8-13 Kanda-Surugadai, Chiyoda-ku, Tokyo 101-8310, Japan

Tel: +81-3-3219-8107

Fax: +81-3-3219-8349

E-mail: shimada-ki@dent.nihon-u.ac.jp receptors. Upon ligand binding and activation, TGF- $\beta$ type II receptor (TGF $\beta$-IIR) kinase phosphorylates the TGF- $\beta$ type I receptor (TGF $\beta$-IR), which in turn phosphorylates the receptor-regulated Smads (R-Smads), including Smad2 and Smad3. In contrast, the binding of BMP to BMP type I/II receptors activates Smad1, Smad5, and Smad8. The phosphorylated R-Smads form complexes with the common-partner Smad (Co-Smad, Smad4 only in mammals), which then act as signal transducers in both the TGF- $\beta$ and BMP pathways (1-5). These complexes translocate to and accumulate in the nucleus, where they regulate the transcription of various target genes such as transcription factors closely related to osteoblast differentiation and maturation and bone development. The main transcription factors are runt-related transcription factor 2 (Runx2), distal-less homeobox 5 (Dlx5), msh homeobox homolog 2 (Msx2), and trans-acting transcription factor 7 (Sp7, also called Osterix) (6-12).

A previous micro array study (13) showed that the gene expression of CD47 (integrin-associated protein) increased significantly in a time-dependent manner during the period of mandible development. CD $47^{-/-}$mice increased bone mass and defective osteoclast function in vivo and in vitro $(14,15)$. CD47 is involved in increasing the intracellular calcium concentrations after a cell has adhered to the extracellular matrix (16), and it plays a role of receptor for integrin $\alpha v \beta 3$, $\alpha \operatorname{IIb} \beta 3, \alpha 2 \beta 1$, and $\alpha 4 \beta 1$ (17-20). Statin, which might offer protection against osteonecrosis, enhances osteogenic genes such as alkaline phosphatase, type I collagen, osteocalcin, and CD47 in osteoblasts $(21,22)$. These studies suggest that the CD47 might be 
involved in bone metabolism.

To date, however, no report has addressed the association between $C D 47$ and the TGF- $\beta$ /BMP signaling pathway in osteoblasts. Herein, to determine the role of CD47 in this pathway, we have used short-interfering RNA (siRNA) to silence CD47 expression in a mouse osteoblast cell line, MC3T3-E1. We then examined the protein levels of components in the pathway and the expression of the transcription factors. Furthermore, the distribution of CD47 was also analyzed immunohistochemically at the late embryonic stage.

\section{Materials and Methods}

\section{Cell culture}

Mouse osteoblast-like MC3T3-E1 cells were cultured in $\alpha$-minimum essential medium (Gibco BRL, Rockville, MD, USA) containing $10 \%$ heat-inactivated fetal bovine serum (JRH Biosciences, Lexena, KS, USA) and 1\% penicillin-streptomycin solution (Sigma-Aldrich, St Louis, MO, USA). The cultures were maintained at $37^{\circ} \mathrm{C}$ in a humidified atmosphere of $95 \%$ air and $5 \% \mathrm{CO}_{2}$.

\section{CD47 gene silencing}

The endogenous transcription of CD47 was disrupted in MC3T3-E1 cells using a 21-nucleotide siRNA, r(GGAAUGACCUCUUUCACCA) dTdT (SigmaGenosys., The Woodland, TX, USA). The cells were transfected with AllStars Negative Control siRNA (Qiagen, Tokyo, Japan) as a negative control or with 20 or $100 \mathrm{nM}$ of CD47 siRNA using Lipofectamine ${ }^{\mathrm{TM}} 2000$ (Life Technologies., Rockville, MD, USA) according to the manufacturer's protocol.

\section{Real-time PCR}

Total RNA was isolated from cultured MC3T3-E1 cells at $24 \mathrm{~h}$ after transfection with CD47 siRNA using a FastPure ${ }^{\circledR}$ RNA Kit (Takara Bio, Shiga, Japan) according to the manufacturer's instructions. Aliquots containing equal amounts of mRNA were subjected to reverse transcription and real-time PCR analysis. The RNA (1.0 $\mu \mathrm{g} /$ reaction) was reverse-transcribed at $42^{\circ} \mathrm{C}$ for $60 \mathrm{~min}$ using a T-Primed First-Strand Kit (GE Healthcare., Milwaukee, WI, USA). Quantitative real-time PCR (qRTPCR) was performed using $1.0 \mu \mathrm{l}$ of cDNA template, TaqMan ${ }^{\circledR}$ Universal PCR Master Mix (Life Technologies), and primer/probe sets (Life Technologies) for the target genes $C d 47$, Bmp2, $T g f b 1$, and transcription factors such as runx2, dlx5, msx 2 or sp7. Gapdh was used as an internal control. PCR amplifications were performed in a capped 96-well optical plate and incubated as follows: $5 \mathrm{~min}$ at $50^{\circ} \mathrm{C}, 10 \mathrm{~min}$ at $95^{\circ} \mathrm{C}$, followed by 40 cycles of $15 \mathrm{~s}$ at $95^{\circ} \mathrm{C}$ and 1 min at $60^{\circ} \mathrm{C}$. The gene-specific PCR products were measured continuously using an ABI PRISM 7700 detection system (Life Technologies). Samples were normalized against the internal control, and the results were expressed relative to the data for the transfection of negative siRNA. The data represent the mean \pm standard deviation from three independent experiments. Statistical significance was determined using Bonferroni's modification of Student's $t$-test, and $P<0.05$ was considered to be statistically significant.

Enzyme-linked immunosorbent assay (ELISA)

At $48 \mathrm{~h}$ after the cells were transfected with 20 or 100 nM of CD47 siRNA or with negative control siRNA, the concentrations of BMP- 2 and TGF- $\beta 1$ in the medium were measured using commercial ELISA kits (R\&D Systems., Minneapolis, MN, USA) according to the manufacturer's instructions. Quadruplicate assays were performed for each sample, and Bonferroni's modification of Student's $t$-test was used as a statistical test.

\section{SDS-PAGE and Western blotting of whole-cell extracts}

Cells were transfected with 20 or $100 \mathrm{nM}$ of CD47 siRNA or with negative control siRNA and incubated for $48 \mathrm{~h}$. To obtain whole-cell extracts, the cells were rinsed with phosphate-buffered saline, suspended in lysis buffer, and sonicated as above. Aliquots containing equal amounts of protein in SDS-PAGE sample buffer were subjected to SDS-PAGE and Western blotting. Western blotting was performed using the following primary antibodies: rabbit polyclonal anti-CD47, rabbit anti-phospho-Smad1 (Santa Cruz Biotechnology, Santa Cruz, CA, USA), mouse monoclonal anti-Smad2 (BD Transduction Laboratories, Lexington, KY, USA), rabbit anti-phospho-Smad2 (Cell Signaling, Beverly, MA, USA), and mouse monoclonal anti- $\beta$-actin (Santa Cruz Biotechnology), all with horseradish peroxidase-conjugated secondary antibodies (GE Healthcare for mouse- and rabbit-IgG). Immunoreactive proteins were visualized using a chemiluminescence kit (ECL Western Blotting Reagent Kit; GE Healthcare) and exposed to X-ray film.

\section{Immunohistochemical analysis of CD47 in mouse embryos}

Pregnant Swiss-Webster mice were used for this study. The females were mated for $2 \mathrm{~h}$ and the presence of vaginal plug was used to determine E0. To examine the Meckel's cartilage immunohistochemistry, tissues were dissected at E13 and E15. They were sectioned in the transverse plane at $7 \mu \mathrm{m}$ on a freezing Cryostat and immunostained 
according to the avidin-biotin peroxidase method. The sections were blocked in Serum Blocking Solution (Zymed., San Francisco, CA, USA) for $30 \mathrm{~min}$, followed by overnight incubation with CD47 primary antibody at room temperature. The slides were laid in the chamber, and the secondary antibody (Zymed) was added for $10 \mathrm{~min}$, followed by the enzyme conjugate for $10 \mathrm{~min}$. Finally, the substrate mixture was added for approximately $15 \mathrm{~min}$. The tissue was stained additionally by hematoxylin as a counterstain. The mount slides were covered with aquamount and cover slips.

(a)

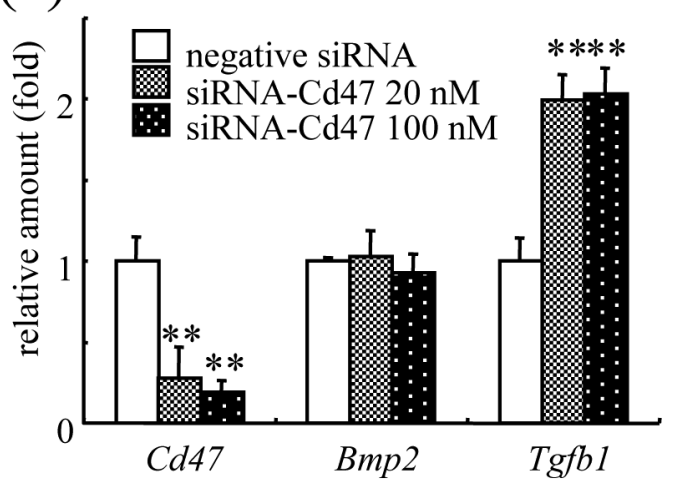

(b)

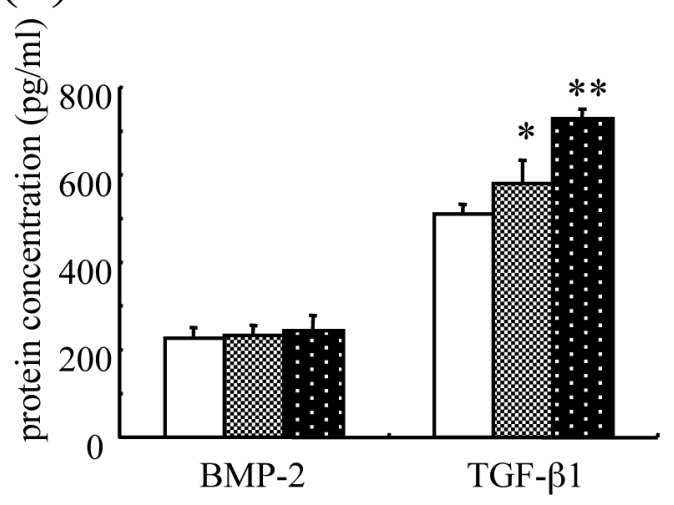

Fig. 1 CD47 silencing increases the expression of TGF- $\beta 1$. MC3T3-E1 osteoblasts were transfected with 20 or 100 nM CD47 siRNA or with negative control siRNA for 24 or 48 h. (a) Gene expression of Bmp2 and $T g f b 1$ in the presence of CD47 siRNA. Total RNA was isolated after $24 \mathrm{~h}$, and qRT-PCR was performed. Gene expression was quantified relative to the internal control $($ Gapdh) and is represented as multiples of the expression level compared to the negative control siRNA $(n=3)$. (b) BMP-2 and TGF- $\beta 1$ protein levels in the supernatant. The proteins were detected using a commercial ELISA kit $(n=5)$. $* P<0.05 ; * * P<$ 0.01 .

\section{Results}

CD47 silencing increases TGF- $\beta 1$ expression

To determine the function of CD47 in osteoblasts, CD47 was silenced in MC3T3-E1 cells using siRNA, and the protein in the medium and the levels of expression for BMP2 and TGF- $\beta 1$ were determined by qRT-PCR and ELISA. The protein and gene expression levels for TGF- $\beta 1$ increased dose-dependently $(P<0.05)$, but the protein and gene levels for BMP-2 did not change significantly (Fig. $1 a, b)$.

Next, the protein expression levels of CD47, phosphoSmad1, phospho-Smad2, and Smad2 were determined by Western blotting. CD47 protein expression was silenced in a dose-dependent manner, and the phospho-Smad2 level increased dose-dependently by the siRNA to the same levels as TGF- $\beta 1$. Smad 2 and $\beta$-actin protein expression did not change (Fig. 2). These results suggest that CD47 down-regulates the TGF- $\beta 1$ signaling pathway in osteoblasts.

CD47 silencing increases the gene expression of transcription factors

The gene expression levels of runx $2, d l x 5, m s x 2$, and $s p 7$ were determined by qRT-PCR. The levels of all

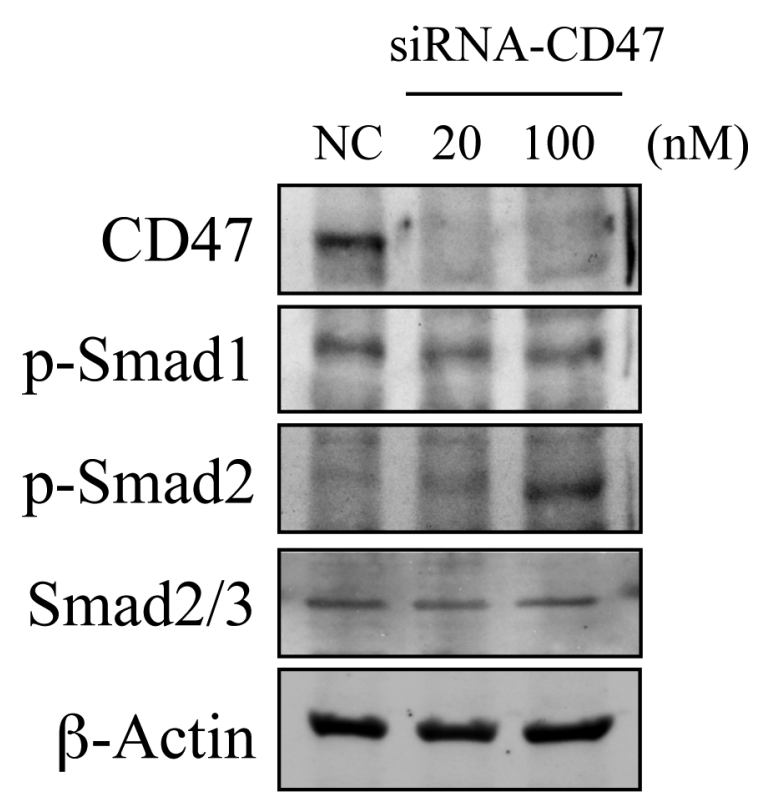

Fig. 2 CD47 silencing increases the levels of phospho-Smad2 proteins. The phosphorylation of Smad1 and Smad2 in the presence of CD47 siRNA. Whole-cell lysates were prepared after $48 \mathrm{~h}$. The samples were normalized by the total protein concentration, subjected to SDSPAGE, and immunoblotted with anti-CD47, antiphospho-Smad1, anti-phospho-Smad2, or anti-Smad2/3 antibodies. $\beta$-Actin served as a control. 
transcription factors increased with CD47 siRNA treatment in a dose-dependent manner (Fig. 3, $P<0.05$ ), suggesting that CD47 down-regulates these transcription factors, which are related to bone metabolism and maturation.

\section{Localized distribution of CD47 in mouse embryo}

To determine the distribution of CD47 in vivo, we conducted an immunohistological analysis using mouse embryonic E13 and E15. The CD47-positive cells were chondrocyte-like cells and were localized below the tongue at E13 and E15 (Figs. 4a, c), suggesting that the CD47positive cells might be Meckel's cartilage. A patch of CD47-positive cells was also localized at the side of the cartilage at E15 (Figs. 4a, b). Therefore, the CD47-positive cells might be the origin of mandible.

\section{Discussion}

The silencing of the CD47 gene increased the levels of TGF- $\beta 1$ and phospho-Smad2, but not BMP-2 and phosphoSmad1, and the gene expressions of transcription factors related to osteoblastic differentiation and maturation increased significantly in osteoblasts. Furthermore, we demonstrated that CD47 was distributed in Meckel's cartilage at mouse stages E13 and E15 and in the embryonic mandible at the E15 stage. These results suggest for the first time that CD47 might regulate the TGF- $\beta$ signaling pathway and influence the development of the mandible.

Normally, TGF- $\beta 1$ is secreted as a complex of three proteins, including the bioactive peptide of TGF- $\beta 1$, a latency-associated peptide $\beta 1$ (LAP- $\beta 1$ ), and a latent TGF-

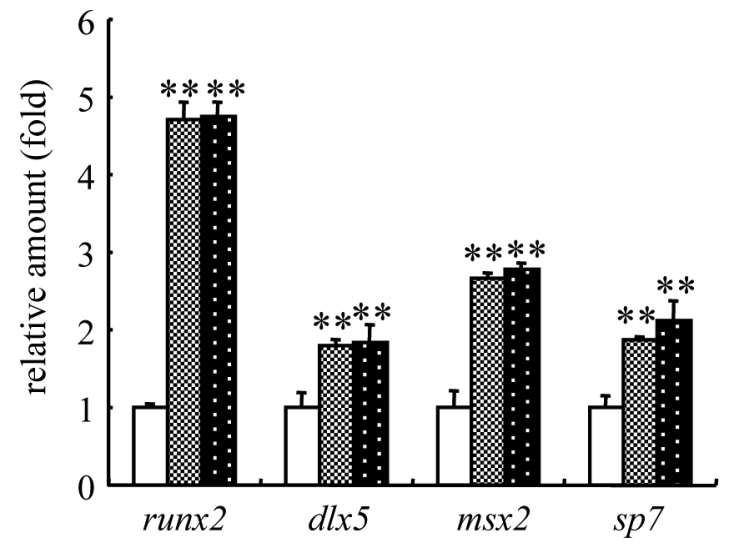

Fig. 3 Gene expression of transcription factors, which is related to bone metabolism, in the presence of CD47 siRNA. Total RNA was isolated after $24 \mathrm{~h}$, and qRTPCR was performed. Gene expression was quantified relative to the internal control (Gapdh) and is shown as multiples of the expression level compared to the negative control siRNA $(n=3)$. $* P<0.05$; ** $P<0.01$.
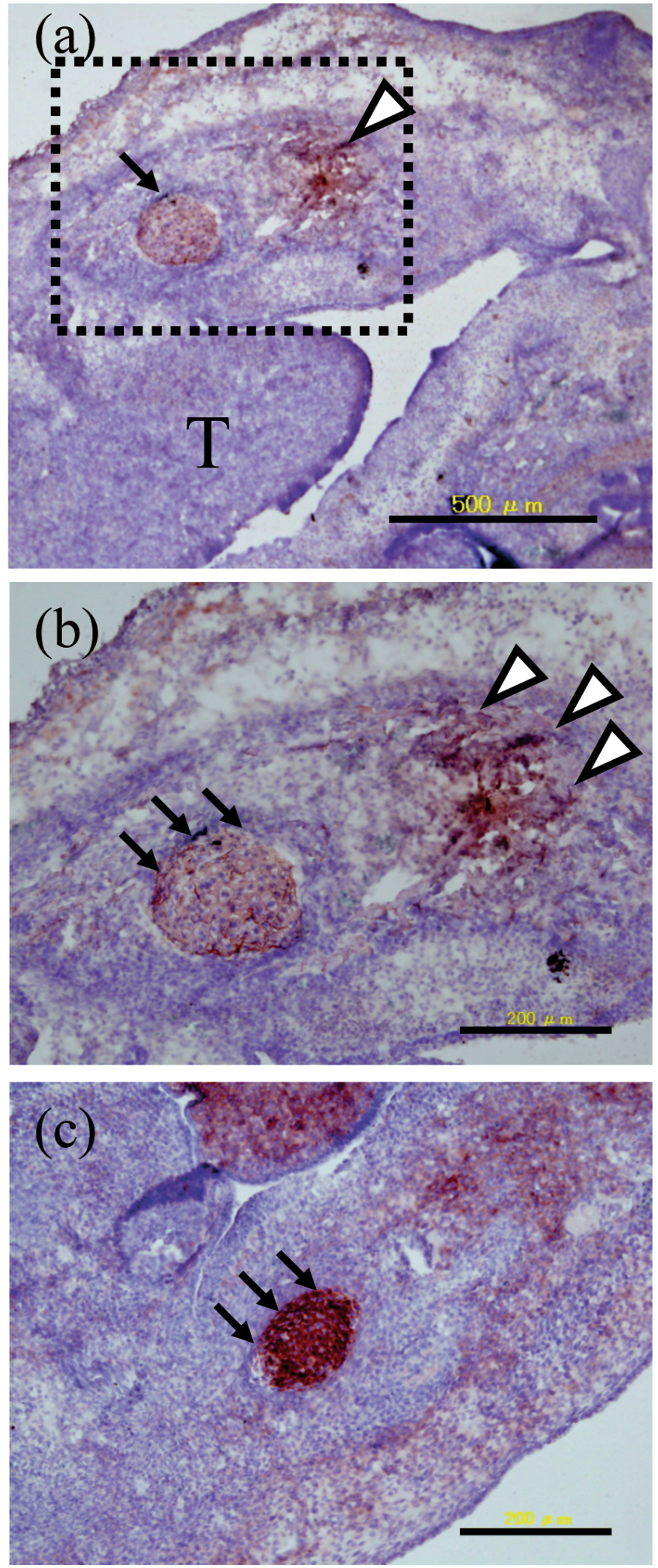

Fig. 4 The distribution of CD47 in mouse embryonic mandible. Mouse embryonic mandible was analyzed immunohistochemically. (a, b) CD47-positive chondrocyte-like cells in Meckel's cartilage (black arrows) and antenatal mandible bone (white arrow heads) at E15 and (c) in Meckel's cartilage at E13. T: tongue, bars: (a) $500 \mu \mathrm{m}$, (b, c) $200 \mu \mathrm{m}$. 
$\beta$ binding protein-1 (23). LAP- $\beta 1$ is recognized by $\alpha \mathrm{V}-$ containing integrins such as $\alpha v \beta 1, \alpha v \beta 3, \alpha v \beta 5, \alpha v \beta 6$, and $\alpha v \beta 8$ (24-27). Furthermore, TGF- $\beta 1$ enhances the cell surface expression of $\alpha \mathrm{v}, \beta 1$, or $\beta 3$ integrin subunits in osteoclasts or human breast cancer cells $(28,29)$. CD47 and TGF- $\beta 1$ might be associated through the $\alpha v$ integrin subunit because CD47 is a receptor for integrin $\alpha v \beta 3$ $(16,20)$. Our data also suggest that CD47 might be able to regulate the TGF signaling pathway because the CD47 silencing increased dramatically the protein expression of TGF- $\beta 1$ and the phosphorylation of Smad2. To understand the cross-talk mechanism in detail, further study is needed.

CD $47^{-/-}$mice displayed increased bone mass and diminished osteoclast function $(14,15)$. There is no knowledge of the osteoblast function in $\mathrm{CD} 47^{-/}$mice, but our data demonstrated that the transcription factors for bone differentiation and maturation of osteoblasts increased upon CD47 silencing using siRNA. The function of osteoblasts in $\mathrm{CD} 47^{-/}$mice may be enhanced in vivo because intercellular communication exists between osteoblasts and osteoclasts (30).

Smad2 KO mutant embryos fail to form an organized egg cylinder and lack mesoderm. Interestingly, some of the Smad2 heterozygous embryos have severely defective mandibles or eyes, suggesting that the dosage of Smad2 is critical for normal craniofacial development (31). Although both TGF- $\beta$ and BMPs specific Smads are present in cartilage, different pathway-specific Smads may have different functions in regulating chondrogenesis (32). Here, we focused on CD47 and TGF- $\beta$ including the Smads pathway. Collectively, our analysis suggests that CD47 and TGF- $\beta$ signaling may play important regulatory roles during the development of Meckel's cartilage. The function of CD47 in bone formation, including Meckel's cartilage development, and the delay and disposition of the initial mandible formation might be due to malformation of Meckel's cartilage (primordium for mandibular development) and may account for the malformation of mandible as reported in Smad2 heterozygous mutant mice (33). A direct correlation was observed between the expression level of Smad2 and the delay in Meckel's cartilage formation, and the Smad2 heterozygous mutant mandibular explants with at least half (or more than half) of the normal Smad2 expression level did not show any alteration of Meckel's cartilage development (34). Exogenous TGF- $\beta 1$ was added to Smad 2 heterozygous mutant mandibular explants culture medium and did not rescue the development of Meckel's cartilage, indicating that an adequate level of Smad2 expression is critical in regulating TGF- $\beta$-mediated chondrogenesis $(31,34,35)$. Thus, we identified that CD47 is strongly associated with
TGF- $\beta$ signaling following Meckel's cartilage development in mouse embryo.

In conclusion, our data suggest that CD47 down-regulates the TGF- $\beta$ signaling pathway and the transcription factors of bone differentiation and maturation in vitro and that CD47 distributes in antenatal Meckel's cartilage in vivo. CD47 may be a key factor in the cross-talk between TGF$\beta$ and the integrin signaling pathway, although further studies will be needed.

\section{Acknowledgments}

This work was supported by Grant from Dental Research Center, Nihon University School of Dentistry, Tokyo, Japan.

\section{References}

1. Lian JB, Stein GS, Javed A, van Wijnen AJ, Stein JL, Montecino M, Hassan MQ, Gaur T, Lengner CJ, Young DW (2006) Networks and hubs for the transcriptional control of osteoblastogenesis. Rev Endocr Metab Disord 7, 1-16.

2. Miyazawa K, Shinozaki M, Hara T, Furuya T, Miyazono K (2002) Two major Smad pathways in TGF- $\beta$ superfamily signaling. Genes Cells 7, 11911204.

3. Shi Y, Massagué J (2003) Mechanisms of TGF- $\beta$ signaling from cell membrane to the nucleus. Cell 113, 685-700.

4. Chen D, Zhao M, Mundy GR (2004) Bone morphogenetic proteins. Growth Factors 22, 233241.

5. Miyazono K, Maeda S, Imamura T (2005) BMP receptor signaling: transcriptional targets, regulation of signals, and signaling cross-talk. Cytokine Growth Factor Rev 16, 251-263.

6. Ducy P, Zhang R, Geoffroy V, Ridall AL, Karsenty G (1997) Osf2/Cbfa1: a transcriptional activator of osteoblast differentiation. Cell 89, 747-754.

7. Komori T, Yagi H, Nomura S, Yamaguchi A, Sasaki K, Deguchi K, Shimizu Y, Bronson RT, Gao YH, Inada M, Sato M, Okamoto R, Kitamura Y, Yoshiki S, Kishimoto T (1997) Targeted disruption of Cbfa1 results in a complete lack of bone formation owing to maturational arrest of osteoblasts. Cell 89, 755764.

8. Phimphilai M, Zhao Z, Boules H, Roca H, Franceschi RT (2006) BMP signaling is required for RUNX2-dependent induction of the osteoblast phenotype. J Bone Miner Res 21, 637-646.

9. Komori T (2010) Regulation of osteoblast differentiation by runx2. Adv Exp Med Biol 658, 
43-49.

10. Shirakabe K, Terasawa K, Miyama K, Shibuya H, Nishida E (2001) Regulation of the activity of the transcription factor Runx 2 by two homeobox proteins, Msx2 and Dlx5. Gene Cells 6, 851-856.

11. Shimada K, Suzuki N, Ono Y, Tanaka K, Maeno M, Ito K (2008) Ubc9 promotes the stability of Smad4 and the nuclear accumulation of Smad1 in osteoblastlike Saos- 2 cells. Bone 42, 886-893.

12. Shimada K, Ikeda K, Ito K (2009) Traf2 interacts with Smad4 and regulates BMP signaling pathway in MC3T3-E1 osteoblasts. Biochem Biophys Res Commun 18, 775-779.

13. Kaburagi H, Sugano N, Oshikawa M, Koshi R, Senda N, Kawamoto K, Ito K (2007) Microarray analysis of the developing rat mandible. Acta Biochim Biophys Sin (Shanghai) 39, 399-405.

14. Uluçkan Ö, Becker SN, Deng H, Zou W, Prior JL, Piwnica-Worms D, Frazier WA, Weilbaecher KN (2009) CD47 regulates bone mass and tumor metastasis to bone. Cancer Res 69, 3196-3204.

15. Lundberg P, Koskinen C, Baldock PA, Löthgren H, Stenberg A, Lerner UH, Oldenborg PA (2007) Osteoclast formation is strongly reduced both in vivo and in vitro in the absence of CD47/SIRP $\alpha$ interaction. Biochem Biophys Res Commun 352, 444-448.

16. Brown EJ, Frazier WA (2001) Integrin-associated protein (CD47) and its ligands. Trends Cell Biol 11, 130-135.

17. Chung J, Gao AG, Frazier WA (1997) Thrombspondin acts via integrin-associated protein to activate the platelet integrin $\alpha \mathrm{IIb} \beta 3$. J Biol Chem 272, 14740-14746.

18. Wang XQ, Frazier WA (1998) The thrombospondin receptor CD47 (IAP) modulates and associates with $\alpha 2 \beta 1$ integrin in vascular smooth muscle cells. Mol Biol Cell 9, 865-874.

19. Brittain JE, Han J, Ataga KI, Orringer EP, Parise LV (2004) Mechanism of CD47-induced $\alpha 4 \beta 1$ integrin activation and adhesion in sickle reticulocytes. $\mathrm{J}$ Biol Chem 279, 42393-42402.

20. McDonald JF, Zheleznyak A, Frazier WA (2004) Cholesterol-independent interactions with CD47 enhance $\alpha v \beta 3$ avidity. J Biol Chem 279, 1730117311.

21. Pritchett JW (2001) Statin therapy decreases the risk of osteonecrosis in patients receiving steroids. Clin Orthop Relat Res 386, 173-178.

22. Kim HK, Cho SG, Kim JH, Doan TK, Hu QS, Ulhaq R, Song EK, Yoon TR (2009) Mevinolin enhances osteogenic genes (ALP, type I collagen and osteocalcin), CD44, CD47 and CD51 expression during osteogenic differentiation. Life Sci 84, 290295.

23. Annes JP, Munger JS, Rifkin DB (2003) Making sense of latent TGF $\beta$ activation. J Cell Sci 116, 217-224.

24. Mu D, Cambier S, Fjellbirkeland L, Baron JL, Munger JS, Kawakatsu H, Sheppard D, Broaddus VC, Nishimura SL (2002) The integrin $\alpha v \beta 8$ mediates epithelial homeostasis through MT1MMP-dependent activation of TGF- $\beta 1$. J Cell Biol 157, 493-507.

25. Munger JS, Harpel JG, Giancotti FG, Rifkin DB (1998) Interactions between growth factors and integrins: latent forms of transforming growth factor$\beta$ are ligands for the integrin $\alpha v \beta 1$. Mol Biol Cell 9, 2627-2638.

26. Ludbrook SB, Barry ST, Delves CJ, Horgan CM (2003) The integrin $\alpha v \beta 3$ is a receptor for the latency-associated peptides of transforming growth factors $\beta 1$ and $\beta 3$. Biochem J 369, 311-318.

27. Annes JP, Chen Y, Munger JS, Rifkin DB (2004) Integrin $\alpha v \beta 6$-mediated activation of latent TGF$\beta$ requires the latent TGF- $\beta$ binding protein-1. J Cell Biol 165, 723-734.

28. Chin SL, Johnson SA, Quinn J, Mirosavljevic D, Price JT, Dudley AC, Thomas DM (2003) A role for $\alpha \mathrm{V}$ integrin subunit in TGF- $\beta$-stimulated osteoclastogenesis. Biochem Biophys Res Commun 307, 1051-1058.

29. Wei YY, Chen YJ, Hsiao YC, Huang YC, Lai TH, Tang CH (2008) Osteoblasts-derived TGF- $\beta 1$ enhance motility and integrin upregulation through Akt, ERK, and NF-kB-dependent pathway in human breast cancer cells. Mol Carcinog 47, 526-537.

30. Phan TC, Xu J, Zheng MH (2004) Interaction between osteoblast and osteoclast: impact in bone disease. Histol Histopathol 19, 1325-1344.

31. Chai Y, Mah A, Crohin C, Groff S, Bringas P Jr, Le T, Santos V, Slavkin HC (1994) Specific transforming growth factor- $\beta$ subtypes regulate embryonic mouse Meckel's cartilage and tooth development. Dev Biol 162, 85-103.

32. Flanders KC, Kim ES, Roberts AB (2001) Immunohistochemical expression of Smad 1-6 in the 15-day gestation mouse embryo: signaling by BMPs and TGF- $\beta$ s. Dev Dyn 220, 141-154.

33. Nomura M, Li E (1998) Smad2 role in mesoderm formation, left-right patterning and craniofacial development. Nature 393, 786-790. 
34. Ito Y, Bringas P Jr, Mogharei A, Zhao J, Deng C, Chai Y (2002) Receptor-regulated and inhibitory Smads are critical in regulating transforming growth factor $\beta$-mediated Meckel's cartilage development. Dev Dyn 224, 69-78.
35. Oka K, Oka S, Sasaki T, Ito Y, Bringas P Jr, Nonaka $\mathrm{K}$, Chai Y (2007) The role of TGF- $\beta$ signaling in regulating chondrogenesis and osteogenesis during mandibular development. Dev Biol 303, 391-404. 